\title{
Correction to: Protective effects of crocin against endogenous A $\beta$-induced neurotoxicity in N2a/APP695swe cells
}

\author{
Jikun $\mathrm{Du}^{1,2} \cdot$ Yuanhua $\mathrm{Li}^{1} \cdot$ Daibo Song ${ }^{1} \cdot$ Jierong Liu ${ }^{1} \cdot \mathrm{Qunfa}$ Huang ${ }^{1} \cdot$ Jinwen $\mathrm{Li}^{1} \cdot$ Baohong $\mathrm{Li}^{1} \cdot \mathrm{Li} \mathrm{Li}^{1}$ \\ Published online: 9 August 2021 \\ ๑) Springer-Verlag GmbH Germany, part of Springer Nature 2021 \\ Correction to: Psychopharmacology \\ https://doi.org/10.1007/s00213-021-05899-4
}

The authors wanted to change the affiliation sequence.

The original article has been corrected.

Publisher's note Springer Nature remains neutral with regard to jurisdictional claims in published maps and institutional affiliations.

The original article can be found online at https://doi.org/10.1007/ s00213-021-05899-4.

Baohong Li

gdmcli@126.com

$\triangle \mathrm{Li} \mathrm{Li}$

china_lovelylily@hotmail.com

1 School of Pharmacy, Institute of Traditional Chinese Medicine and New Pharmacy Development, Guangdong Medical University, Dongguan, China

2 Central Research Laboratory, Shenzhen Hospital of Integrated Traditional Chinese and Western Medicine, The Second People's Hospital of Bao'an Shenzhen (Group) Shajing People's Hospital of Bao'an Shenzhen, Shenzhen, China 